\title{
The Adoption of Web-Based Marketing in the Travel and Tourism Industry: An Empirical Investigation in Egypt
}

\author{
Rania Hussein ${ }^{1}$, Christine Ennew ${ }^{2}$ and Wael Kortam ${ }^{3}$ \\ ${ }^{1}$ Business Administration Department, Cairo University, Egypt \\ ${ }^{2}$ Nottingham University Business School, University of Nottingham, UK \\ ${ }^{3}$ Faculty of Business and Economics, Heliopolis University for Sustainable Development, Egypt
}

\begin{abstract}
This paper seeks to explain the determinants of the levels of web adoption for marketing purposes by small and medium sized enterprises (SMEs) in the travel and tourism industry. Web adoption is specifically defined as the ownership of a website to communicate and/or deliver travel services to a target market. Additionally, the levels of adoption represent the different levels that SMEs go through in their adoption process starting with not owning a website to being a simple adopter to being a sophisticated adopter. A distinctive model is developed drawing on Roger's innovation adoption model, the resource based view of the firm (RBV) and the results of previous empirical work. The model proposes that the adoption decision is dependent on a combination of perceived attributes of the innovation, organization specific characteristics which are derived from a resource-based view of the firm as well as decision maker characteristics. Both logistic and multiple regression are used to test the model and the resulting hypotheses. Analysis results indicate that innovation attributes are not the whole story when studying firms' adoption of the web for marketing purposes, firm resources also affect the adoption decision. Additionally, different factors affect different levels of adoption so that when studying innovation adoption by firms, it is important to consider the adoption process as a continuous process that consists of different levels rather than a dichotomous process of adopt vs. non-adopt.
\end{abstract}

Keywords: Innovation, web, tourism, perceived attributes of innovations, resource-based view of the firm.

\section{Introduction}

The advent of the Internet and the World Wide Web has attracted considerable attention and research from both academics and practitioners. Numerous studies anticipated a "marketing revolution" (Hoffman and Novak, 1997; Keeny and Marshall, 2000) as businesses changed their modes of operation and customers adapted to novel and different ways of purchasing goods and services. This research utilized a variety of theoretical frameworks including Roger's Perceived Attributes of Innovations (PAI) model, the Technology Acceptance model (TAM) and the theories of reasoned action and planned behaviour. More recently, researchers have started to focus on the willingness of businesses to adopt the web for both general and marketing specific

Copyright (C) 2012 Rania Hussein, Christine Ennew and Wael Kortam. This is an open access article distributed under the Creative Commons Attribution License unported 3.0, which permits unrestricted use, distribution, and reproduction in any medium, provided that original work is properly cited. Contact author: Rania Hussein E-mail: Raniasamir@hotmail.com 
purposes, recognizing that not all businesses will immediately appreciate the advantages of the new technology (Dubelaar et al., 2005; Ferneley and Bell, 2006; Lefebrve et al., 2005).

This paper seeks to investigate the issues relating to the adoption of an innovation like the web for marketing purposes by businesses. In particular this paper focuses on the factors that affect different levels of web adoption by firms. It builds primarily on existing end consumer based research and develops a conceptual framework to understand why businesses do or do not adopt the web for marketing purposes and the levels of adoption that exist. It is worth noting here that web adoption is measured as a continuum in this research unlike previous researches that have studied it as a dichotomous variable. A novel approach is used to measure the degree of adoption by measuring the extent to which travel companies are actually engaged over the web through their sales done online with those highly selling being considered highly engaged. This is a measure of degree of sophistication of adoption that is based around sales.

The conceptual framework is developed based on three major sources, namely dominant existing innovation diffusion models and in particular Roger's theory of innovation adoption, the Resource-based view of the firm and extant innovation adoption literature. The paper begins with a brief overview of approaches to the adoption of technology- based innovations to establish the current theoretical context for work in this area. The conceptual framework is then presented. Following that, the quantitative methodology employed is then reviewed and the results discussed. The paper concludes with a discussion of the implications of the findings and directions for future research.

\section{Literature Review}

The literature review has three broad themes to it, being innovation adoption, SMEs and
RBV. First, innovation adoption as studied in literature will be defined and the common ways of measuring it by previous researches will be discussed. Next, since this is a business to business study that focuses on web adoption by organizations, particularly SMEs, a discussion on the importance of SMEs, their different characteristics compared to large organizations and research focus on SMEs and internet adoption will follow. Finally, the resourcebased view of the firm, which is a framework in strategy literature, will help us better understand how firm specific characteristics can affect innovation adoption.

Innovation adoption has been conceptualized in different ways and studied from several perspectives. In addition to the distinction between end consumer studies and organizational studies, distinctions have been made between innovation adoption at different levels of analysis for example, comparing the organization and individuals within the organization (Frambach and Schillewaert, 2002), studies of adoption versus diffusion of innovations (Kimberly and Evanisko, 1981), innovation as a dichotomous variable indicating either adoption or non-adoption versus as a process of distinct and separate stages (Huizingh and Brand , 2009; Molla and Licker, 2005; AguilaObra and Padilla-Melendez, 2006).

Since the introduction of disruptive technologies such as the Internet and ecommerce is often followed by a series of incremental innovations, the adoption of such technologies is not a binary process, but one that involves multiple levels (Brand and Huizingh, 2008). Relatively few researchers have studied this model of levels of adoption in a web context (Houghton and Winklhofer, 2002; Doherty et al., 2003; Molla and Licker, 2005; Aguila-Obra and Padilla-Melendez, 2006; Huizingh and Brand, 2009) and those who have examined web adoption as consisting of different levels have tended to concentrate on a developed country context. Additionally, these studies have other limitations such as acknowledging the 
existence of different levels but not attempting to study the factors that affect these different levels (Hamill and Gregory, 1997), and not attempting to quantitatively test these factors (Houghton and Winklhofer, 2002).

A number of different theoretical perspectives have been utilized to study the adoption of innovations. Rogers' Perceived Attributes of Innovations model (PAI) has been widely used in studies of, for example, telephone banking (Locket and Littler, 1997) online financial services (Frambach et al., 1998, Black et al., 2001). More general, but perhaps less popular, classical attitudebehaviour theories such as the Theory of Planned Behaviour (TPB) and the Theory of Reasoned Action (TRA) have also been used to understand end consumers adoption decisions (eg Shim et al., 2001, Yoh et al., 2003). More recently, the Technology Acceptance Model (TAM), a derivative of TRA has been used to study the adoption of IT among the sales force (Schillewaert et al., 2005). Probably the dominant theoretical model in consumer-based studies is Roger's model of the perceived attributes of innovation. Rogers (1962) seminal text identifies five characteristics pertinent to the innovation itself that have an effect on its adoption, namely relative advantage, compatibility, trialability, observability and complexity. Subsequent researchers added Bauer's (1960) construct of perceived risk to those proposed by Rogers. The first four attributes are positively related to adoption and the last two are negatively related (Rogers, 1962; Bauer, 1960).

Much of the initial marketing research on the adoption of innovations focused attention on final consumers. Initially, there was a heavy emphasis on the characteristics of individuals (e.g. innovativeness) as determinants of adoption; subsequently, consideration of demand side (i.e. adopter) characteristics was extended to include attitudes, typically in the form of attitudes towards the innovation (Lockett and Littler, 1997). To date, it is apparent that a large number of innovation adoption studies have focused on the consumer as the unit of analysis; comparatively few studies have considered the factors influencing the adoption of innovations by business (Bengtsson et al., 2007; Ferneley and Bell, 2006; Tan et al., 2007). Still less research was undertaken to consider that adoption of innovations for marketing purposes and the levels of that adoption. However, businesses have decision making processes that often differ from those of consumers and accordingly, there is no reason to automatically assume that adoption decisions and processes are the same for the two groups. In particular, as Frambach et al. (1998) note, organizational innovativeness is not the same as individual innovativeness and while consumers are motivated to satisfy individual needs organizations are concerned with value added and organizational needs.

SMEs have always been recognized as an important segment of the economy and will remain the backbone of economic development in many countries throughout the world (Chong and Lin, 2008). Creative use of the Internet may allow SMEs to capitalize on market opportunities (Maguire et al., 2007). Smaller firms have been much slower than larger ones in adopting the Internet and e-commerce and also relevant research has been slower in developing (Fillis and Wagner, 2007). Most of these studies focus on the barriers that small companies can face in their adoption of the internet as well as the benefits they can realize. Others emphasize the importance of the internet especially for small businesses. Key themes include barriers to adoption (Kartiwi and MacGregor, 2007; Walczuch et al., 2000), benchmarking internet use (Webb and Sayer, 1998), the micro-enterprise and Internet use (Dandridge, 2000) and entrepreneurship and the Internet (Colombo, 2001). ICT including the web is believed to be the most cost efficient tool that can aid companies to gain bigger markets and be able to compete with their larger counterparts in attracting customers to their products and services (Tan et al., 2009). Only 
a limited number of studies have attempted to analyze the factors that lead small companies to either adopt or not adopt the web for marketing purposes and the level of web adoption by these companies.

Business related studies which have been implemented tended to highlight the importance of both perceived attributes of innovation as well as organizational characteristics (To and Ngai, 2006; BayoMoriones and Lera-Lopez; 2007; Real et al.; 2006). Such conceptualizations are consistent with consumer-based work which integrates the attributes of the innovation and the personal characteristics of the consumer to understand adoption. While this approach is theoretically grounded in the literature relating to consumer behavior and specifically to the importance of individual personality differences, studies that have suggested that organizational characteristics affect adoption have often not been well theorized. Although it is expected that firm characteristics affect the adoption decision, there is no theoretical framework to help us understand firm characteristics and how these characteristics affect innovation adoption decision by firms. The strategy literature and particularly the concept of the resource-based view of the firm has the potential to provide a theoretical underpinning and broader conceptualization of the role of organizational characteristics in influencing innovation adoption.

The resource-based view of the firm is a theory of competitive advantage that emphasizes the link between a firm's internal resources, strategy, behavior and performance (Wright et al., 1994). It takes an "inside-out" or firm specific perspective by focusing on the internal resources of the firm as the major determinant of its competitive success (Dicksen, 1996). According to the RBV, firm heterogeneity implies that an innovation is cheaper and/or more attractive to some firms than others. That is to say, some firms appear to possess resources that give them comparative advantage in developing new processes or products (Lockett and Thompson, 2001). Thus, even if an innovation appears to be relatively better than currently adopted ideas, a firm may not be able to adopt this innovation if it does not have the mix of assets or capabilities required for that. Therefore, there is potentially an important relationship between a firm's resources and capabilities and its propensity to adopt an innovation such as online marketing.

\section{Proposed Model of Adoption}

Based on the Roger's perceived attributes of innovation framework, RBV and extant innovation adoption literature, a conceptual model is outlined as can be seen in Figure 1 below. This model outlines the first order factors influencing the level of web adoption for marketing purposes by SMEs. In essence, this model is premised on the attractiveness of the innovation, the strengths of the organization and the commitment of individuals within the organization. The model integrates Roger's perceived attributes of innovations framework which in effect measures the attractiveness of the innovation, with the resource-based view of the firm which measures the extent to which the organization has the capability to adopt. The final component relates to individuals and their ability to drive forward and manage an innovation. It should be noted however that with regard to Roger's perceived attributes of innovations, the attribute trialability will be excluded from this study. 


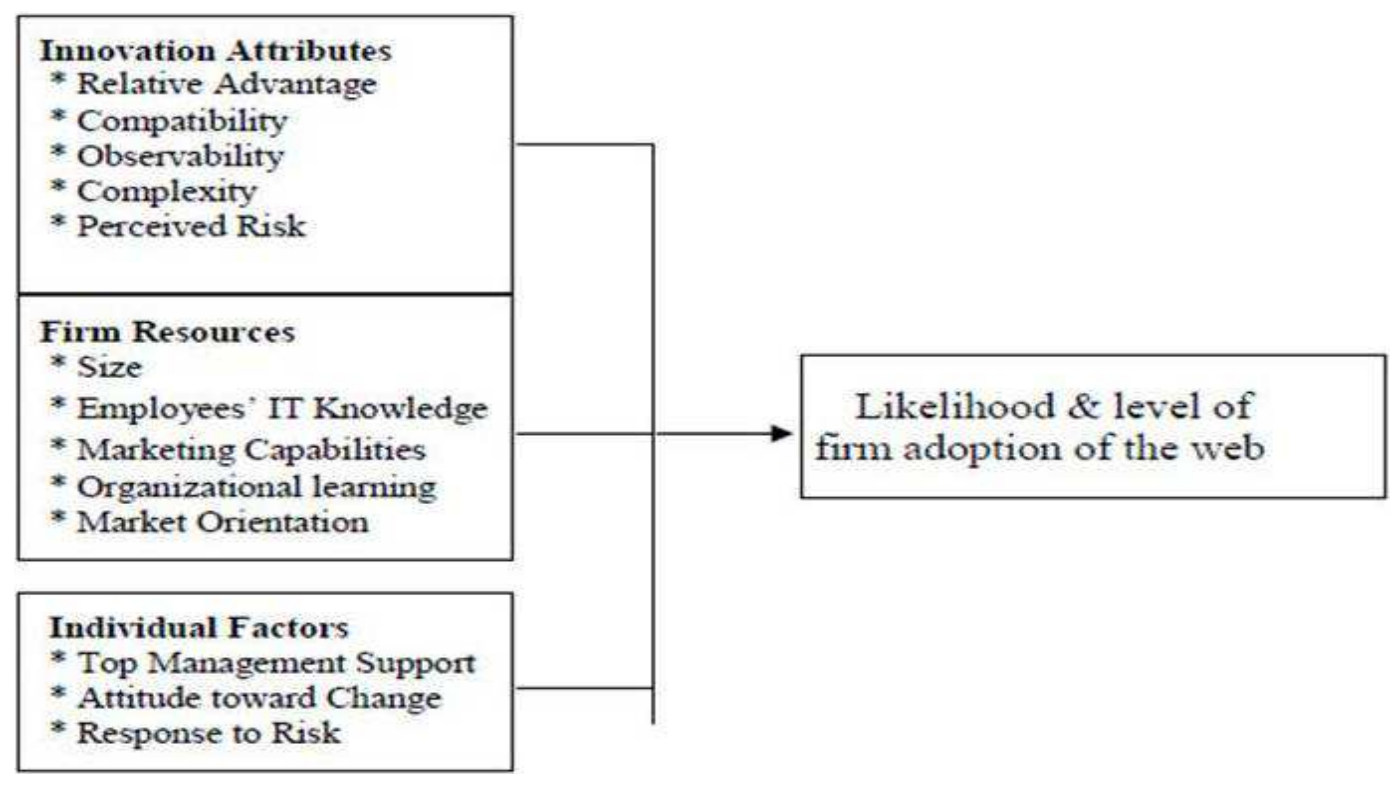

Figure (1): Proposed Conceptual Model of the Factors that Affect Firms' Adoption of the Web
in the Travel Industry

The following is a discussion of the hypotheses tested in this research.

\section{Innovation Attributes}

The innovation attributes included in the model are four attributes suggested by Rogers (2003, p.221) as well as Bauer's perceived risk. It should be noted, however, that the attribute trialability in Roger's perceived innovations attributes framework will be excluded for the purpose of this study. This decision was taken partly due to the specific nature of the innovation being a service innovation that cannot be easily tried on a partial basis. Due to the fact that trying a service is not possible without actually consuming the service, this construct by its very nature is difficult to understand and measure. Additionally, it is a difficult concept with regards to complex adoption because it is difficult to try sales over the web and it is a very crude measure by its nature. Thus, the measurement of trialability was seen as problematic and the factor not sensible to include.
The following is a discussion of each of these factors.

Relative advantage has been defined by Rogers (2003, p.229) as "the degree to which an innovation is perceived as being better than the idea it supersedes." Relative advantage thus indicates how much the adopters of an innovation can perceive benefits associated with adopting the innovation in comparison with their current ways of doing business. Roger's seminal text indicates that relative advantage is expected to have a positive relationship on innovation adoption. Several previous innovation adoption studies and in particular those which focus on the web as the innovation studied, found a positive significant relationship between the relative advantage of the innovation and adoption/nonadoption of the innovation (Chong and Pervan, 2007; To and Ngai, 2006; Premkumar and Roberts, 1999). 
Therefore, based on the above, it is expected that

\section{H.1 The Perceived Relative Advantage of the Web will be Positively Related to the Likelihood and Level of Web Adoption.}

Rogers (2003, p.240) defines compatibility as "the degree to which an innovation is perceived as consistent with existing values, past experiences, and needs of potential adopters." Roger's seminal text indicates that a positive relationship is expected to exist between compatibility and innovation adoption. Previous research on the effect of compatibility on innovation adoption did not show consistent results with regards to its effect on innovation adoption. Some researchers found a significant positive relationship (Saffu et al., 2008; Black et al, 2001; Lockett \&Littler, 1997) while others found no relationship (Sultan \& Chan, 2000). This variability in results may be due to the particular nature of the innovation or the context of the study. However, according to Roger's and in line with some of the recent studies that have found a significant positive relationship between compatibility and web adoption (Grandon and Pearson, 2004; Beatty et al., 2001), it is expected that

H.2 The Perceived Compatibility of the Web will be Positively Related to the Likelihood and Level Web Adoption.

Rogers (2003, p.258) defines observability as "the degree to which the results of an innovation are visible to others." The degree to which an innovation is observable, as perceived by members in a social system, positively affects its rate of adoption. The few studies that have examined the effect of observability on innovation adoption found mixed results, indicating either a positive or a non-significant relationship (Chong and Pervan, 2007; Black et el., 2001). In line with Roger's model, it is expected that

\section{H.3 The Perceived Observability of the Web will be Positively Related to the Likelihood and Level of Web Adoption.}

Rogers (2003, p.257) defines complexity as "the degree to which an innovation is perceived as relatively difficult to understand and use." According to him, the complexity of an innovation, as perceived by members in a social system, negatively affects its rate of adoption. Previous research on the effect of complexity on innovation adoption generally found a negative relationship to exist (Thong, 1999; Frambach et al., 1998; Houghton and Winklhofer, 2002) with only a few of those showing a non significant relationship (Premkumar and Roberts, 1999; Sultan and Chan, 2000). It is expected that the more difficult the innovation is perceived to be, the less likely are respondents to adopt it. Thus, in line with Roger's model and previous research results it is expected that

H.4 The Perceived Complexity of the Web will be Negatively Related to the Likelihood and Level of Web Adoption.

Perceived risk may reflect the risk associated with using the innovation or security issues related to the innovation (Lockett \&Littler, 1997). Previous research results showed a negative relationship between perceived risk and innovation adoption (Doherty et al., 2003; Lockett and Littler, 1997). It is expected that the more the perceived risk associated with adopting the innovation, the less likely that respondents are willing to adopt. Perceived risk maybe more relevant in a service context where the service can not be easily evaluated before adoption (Black et al., 2001). Therefore, it is expected that 


\section{H.5 The Perceived Risks Associated with the Web will be Negatively Related to the Likelihood and Level of Web Adoption.}

\section{Firm Resources}

In line with the resource-based view of the firm (RBV), firm resources include five subdimensions that are size, employees' IT knowledge, marketing capabilities within the firm, organizational learning and market orientation. RBV proponents have suggested different factors that fall under a firm's resources (assets/capabilities) and affect its competitive position. Size for example falls under physical assets as described by Barney (1991). Employees IT knowledge falls under human assets as described by Barney (1991). According to Hooley et al. (1998), market orientation and organizational learning fall under a firm's strategic capabilities whereas marketing capabilities fall under a firm's functional capabilities. Real et al. (2006) also indicate that competitive advantage stems from a company's capabilities and skills with organizational learning becoming a fundamental strategic aspect. Size and employees' IT knowledge of the firm have received empirical support in the literature as to their effect on technological innovation adoption and have been mentioned by both adopters and non-adopters as influential factors (Premkumar \&Roberts, 1999; Scupola, 2003; Doherty et al., 2003; Thong, 1999; Goode \&Stevens, 2000). A number of studies have examined the relationship between market orientation, organizational learning and marketing capabilities and innovation and these found a positive relationship (Leskovar-Spacapan and Bastic, 2007; Akgun et al., 2007). The following includes a discussion on each of these factors.

Company size is one of the company's physical capital resources which, according to Barney (1991), includes a number of things such as a firm's plant and equipment, its geographic location, its access to raw materials and its use of physical technology. According to Roger's (2003, p.409), "larger organizations are more innovative."
Many empirical studies showed that size is one of the important factors affecting the adoption of innovations showing a significant positive relation, indicating that the larger the organization and hence the more the resources that it possesses, the more likely it is to adopt an innovation (Malhotra and Singh, 2007; Bayo-Moriones and Lera-Lopez, 2007; Bruque and Moyano, 2007; Tan et al., 2007; Fabiani et al., 2005). Other studies however showed a non-significant relationship between size and innovation adoption (Scupola, 2003; Frambach et al., 1998; Premkumar and Roberts, 1999). Moreover, some researchers argue that smaller organizations are more likely to adopt the web because of the higher structural flexibility of small organizations in comparison to larger ones (Salavou et al., 2004; Damanpour, 1992).

It is important to notice that size indirectly reflects the resources owned by the firm; financial and human. One of the most common measures of size is the number of employees (Kimberly and Evanisko, 1981). Other measures include fixed assets (Thong, 1999) and annual revenues (Hamill and Gregory, 1997). Although size has been argued to be one of the best predictors of innovation adoption, research results on its relationship with adoption have been controversial.

Based on the above arguments and the balance of empirical evidence, it is argued that

H.6 The Size of a Travel Agent will be Positively Related to the Likelihood and Level of Web Adoption.

A company's human assets include the people working in it and their skills and abilities (Hooley et al, 1998). The level of knowledge and experience of employees can act as a facilitator or barrier to experimenting with new ideas. Previous studies on innovation adoption found a significant positive relationship between IT knowledge within the organization and 
innovation adoption (Thong, 1999; Scupola ,2003; Goode and Stevens, 2000; Houghton and Winklhofer, 2002). Additionally, Cragg and King (1993) found that the lack of IT knowledge by either managers or employees had a negative impact on IT adoption. Based on these empirical research results, it is expected that

\section{H.7 Employees' IT Knowledge will be Positively Related to the Likelihood and Level of Web Adoption.}

Marketing capabilities refer to the integrative processes designed to apply the collective knowledge, skills and resources of the firm to the market-related needs of the business, enabling the firm to add value to its goods and services and to meet competitive demands (Day, 1994). Marketing capabilities include knowledge of the competition, customers, skill of segmenting and targeting markets, advertising and pricing and integrating marketing activity (Song et al., 2008). A growing number of researchers indicate that marketing capability contributes to the commercial success of products and services marketed by the firm, to creating superior customer value and thus to firm performance (Krasnikov and Jayachandran, 2008; Ruiz-Ortega and GarciaVillaverde, 2008; Guenzi and Troilo, 2007). However, research examining the impact of marketing capability on innovation is quite limited (Benedetto et al., 2008; Weerawardena, 2003).

According to Poon and MacPherson (2005), innovating firms must develop considerable marketing capability and thus innovations involve not only technological but also nontechnological activities such as marketing capability as well. These authors found a positive relationship between marketing capability and firms' innovation capability. Similarly, Weerawardena (2003) found that there is a significant positive relationship between marketing capability and an organization's capacity to innovate. Weerawardena and O'Cass (2004) argue that learning from markets and having the ability to reach the targeted customers with value added products represented in the firm's marketing capabilities are critical for firms pursuing innovation-based competitive strategy. Therefore, it is expected that

\section{H.8 Marketing Capabilities within the Company will be Positively Related to the Likelihood and Level of Web Adoption.}

Organizational learning involves giving rise to a set of organizational values that influence the propensity of the firm to create and use knowledge. Learning orientation thus affects the degree to which proactive learning occurs within the firm (Sinkula et al., 1997). Three organizational valuescommitment to learning, open-mindedness and shared vision- constitute the core components of learning orientation within a firm.

Chipika and Wilson (2006) argue that firms could only innovate if they have the competencies and capabilities to make use of their learning. Similarly, Real et al. (2006) explain that distinctive competencies are developed through the learning process and this helps the firm to gain competitive advantage and to become more innovative and successful.

Previous researches found that organizational learning influences an organization's innovation capacity. JimenezJimenez et al. (2008) found that organizational learning has a positive impact on innovation and that an organization trying to enhance innovation should improve its organizational learning processes. Akgun et al. (2007) found that organizational learning is positively associated with product innovativeness. Similarly, Salavou and Lioukas (2004) found that learning orientation has a significant positive relationship with SMEs innovation. This finding is in line with Hurley and Hult (1998) suggestion that learning orientation promotes a firm's receptivity to innovation and also similar to Calantone et al. (2002), 
who found that learning orientation has a positive effect on organizational innovation.

Therefore, based on the above it is expected that

\section{H.9 A Positive Orientation toward Organizational Learning will be Positively Related to the Likelihood and Level of Web Adoption.}

Market orientation of the firm involves the activities of market information acquisition and dissemination and the coordinated creation of customer value. It consists of three components: customer orientation, competitor orientation and interfunctional coordination. Customer orientation and competitor orientation include all of the activities involved in obtaining information about buyers and competitors in the target market and disseminating it throughout the business. Interfunctional coordination deals with the coordinated efforts of different departments to create superior value for the customer (Narver and Slater, 1990).

Previous research results indicate that there is a relationship between market orientation of firms and their capacity to innovate. Leskovar-Spacapan and Bastic (2007), in their study on factors affecting the innovation capability of organizations, found that lack of internal organizational capability including market orientation and others are among the important reasons why organizations exhibit lower levels of innovation capability. Based on an empirical study on 744 firms, Jimenez-Jimenez et al. (2008) found that market orientation has a positive impact on firms' innovation capability. Similarly, Salavou and Lioukas (2004) found that market orientation had a significant positive effect on SMEs innovation. This is in line with what Hurley and Hult (1998) indicated when discussing that market orientation is related to a firm's innovativeness.
Therefore, it is expected that

\section{H.10 The Degree of Market Orientation will be Positively Related to the Likelihood and Level of Web Adoption.}

\section{Individual Factors}

In line with Roger's model of adoption rates and previous empirical results, individual factors include three sub-factors that are top management support, decision makers' attitude toward change and response to risk. These factors have received empirical support from past researches indicating a significant positive influence on innovation adoption (Corbitt, 2000; Thong, 1999; Lockett \& Littler, 1997; Brancheau\&Wetherbe, 1990; Sultan \&Chan, 2000). Adopters were found to have strong management support, a more favorable attitude toward change and are better able to cope with risk. The following is an explanation of each of these factors.

Top management support has found strong empirical support as a factor affecting the adoption of innovations. Bengtsson et al. (2007) in their study on the factors that differentiate firms' adopters of advanced web-based marketing operations from nonadopters found that the presence of champions, top management commitment and entrepreneurial support are the top three attributes that differentiate between adopters and non-adopters. Similarly, Bruque and Mayano (2007) found that top management support was among the factors that significantly affected the speed of adoption of information technology in SMEs. Similar results were found in many other empirical innovation adoption studies (Bharati and Chaudhury, 2006; Beatty et al., 2001; Premkumar and Roberts, 1999). 
Interestingly, Toe and Pian (2003), in their study on the factors affecting firm's level of adoption of the web represented in five levels ranging from simple e-mail adoption to using the web to transform business operations, found that top management support does not affect the level of adoption of the web. They explain that by saying there is little difference in top management support among different levels of adoption. According to them, one possible reason is that management is already aware of the importance of the web as it has already been adopted in the first place. Thong (1999) arrived at a similar result when studying the level of adoption of information systems. He found that although CEO and innovation characteristics of the decision maker are important determinants of the decision to adopt information systems, they do not affect the level of adoption.

Based on the above, it is expected that

H.11 Top Management Support will be Positively Related to the Likelihood and Level of Web Adoption.

According to Rogers (2003, p.290), earlier adopters of innovations have more favorable attitude toward change than later adopters. In developing a framework on individual level adoption of innovations within organizations, Frambach and Schillewaert explain that an individual's cognitive beliefs and affects which are reflected in his/her attitude toward the innovation affect his/her acceptance of the innovation.

Previous research results indicate that attitude of the decision maker toward change has an effect on the adoption of innovations. In their study on business to business ecommerce adoption in China, Tan et al. (2007) found that one of the factors that acted as a barrier to the adoption process was the negative attitude toward change where they explain that China's culture is conditioned to slow responses, and therefore has difficulty in dealing with rapid change. Similarly, Schillewaert et al. (2005) in their study on information technology adoption by sales reps from different sales organizations found that attitude toward change had a positive impact on adoption. Generally, previous researches found that the decision maker's attitude toward change has a significant positive impact on innovation adoption (Corbitt, 2000; Lockett \& Littler, 1997; Thong, 1999).

Therefore, it is expected that

\section{H.12 Management's Attitude toward Change will be Positively Related To the Likelihood and Level of Web Adoption.}

According to Rogers (2003, p.290), earlier adopters of innovations are more able to cope with uncertainty and risk than later adopters. Research results indicate that adopters tend to be more venturesome than non-adopters. Wan et al. (2005) in their study on the determinants of firm innovation in Singapore, found that willingness to take risks had a significant positive relationship with organizational innovation. Similar results were found by Sultan and Chan (2000) in their study on information technology adoption by individuals in US software companies where they found that response to risk significantly affected the adoption decision. Tabak and Barr (1996) also found the same results when studying information technology adoption by hospitals in USA. Based on Roger's innovation adoption model and on previous empirical research results, it is expected that

\section{H.13 Management's Response to Risk will be Positively Related to the Likelihood and Level of Web Adoption.}

In order to understand and evaluate the applicability of the RBV and PAI frameworks and to test the likelihood and level of web adoption for marketing purposes by SMEs, the rest of this paper reports on an empirical study undertaken in the tourism sector in Egypt. The purpose of the research is to examine the factors influencing adoption for 
a service sector business in relation to proposed conceptual model.

\section{Method}

Given the nature of this research, a quantitative approach was adopted to test the model and hypotheses. The questionnaire is divided into three sections. The first section measures the dependent variable by identifying adopters from non-adopters and also identifying levels of adoption. The second section focuses on measuring independent variables as outlined in the model. The final section collects descriptive information on firms. As for the measurement of independent variables, key construct were measured using established scales. Thus, measurement items were carefully chosen from well- established scales. Additionally, focusing on the internal consistency reliability, the researchers conducted the Cronbach Alpha method (Table 1). This is a reliability measure that assesses the consistency of the entire scale. The values of the Cronbach Alpha coefficient range from 0 to 1 with 0.7 being a generally accepted lower limit (Hair et al., 1998).

As for the dependent variable, two approaches were used to measure adoption in the questionnaire. First, a simple and crude measure but one that is easy to get data on is ownership of a web site and selling via the web. This is a simplified measure but is a reasonable proxy, because if companies do sell on the web then this indicates that they are actually doing business over the web and making use of the technology rather than just using the web to communicate. Also, this is a commonly accepted and widely used measure and it is data that can be gathered. This measure has been used by other researchers who studied adoption as a dichotomous variable (Frambach et al., 1998; Premkumar and Roberts, 1999; Sultan and Chan, 2000; Teo and Ranganathan, 2004; To and Ngai, 2006). Second, a sophisticated measure which is how much do you sell on the web is used to measure the degree of adoption by measuring the extent to which these companies are actually engaged over the web with those highly selling being considered highly engaged.

\section{Table (1): Cronbach Alpha Coefficients}

\begin{tabular}{|l|l|}
\hline Variables & Cronbach Alpha \\
\hline Relative advantage & 0.852 \\
\hline compatibility & 0.910 \\
\hline Perceived risk & 0.687 \\
\hline Marketing capabilities & 0.862 \\
\hline Employees' IT knowledge & 0.719 \\
\hline Organizational learning & 0.838 \\
\hline Market Orientation & 0.578 \\
\hline Top management support & 0.906 \\
\hline Attitude toward change & 0.726 \\
\hline Response to risk & 0.672 \\
\hline
\end{tabular}

From the previous table, one can conclude that the reliability coefficient is within a satisfactory level, hence supporting the argument that the research instrument is reliable with regard to its internal consistency. The market orientation, scale however, showed a low alpha of 0.578 which might be due to the fact that this construct had to be compressed from four items to three items in order to reach an appropriate length of the questionnaire.

Logistic and multiple regression were used to measure the research model using SPSS. 


\section{Sample}

The population of this research is all travel agents in Egypt who carry out inbound tourism. Companies who do inbound tourism are the ones interested in marketing their services over the Web as they need to attract and bring tourists to Egypt. The Egyptian Travel Agents Association (ETAA) agencies directory (2005-2006) that contains an alphabetical list of all travel agents in Egypt was used in order to determine the sampling frame.

Four criteria will be used to choose companies that will form the sample of this survey as follows:

I. Company size: three different sizes; small, medium and large companies will be chosen.

II. Web adoption status: both adopters and non-adopters will be part of the survey.

III. Location of business: Cairo (largest tourist city in Egypt based on tourists' inflow and largest number of travel companies). Sinai was also chosen at the outset of the survey since it is the second largest destination after Cairo, but after some interviews with companies and people in the travel field, it was found that almost all companies operating in Sinai are branches of the headquarters that are based in Cairo.

\section{Line of business: inbound tourism.}

This research used a non-probability sample which is judgment sample in selecting a sample that is believed to represent the population of interest (Diamantopoulos and Schlegelmilch, 1997). The use of nonprobability sampling will be more suitable in this research due to the availability of certain criteria upon which companies will be chosen as mentioned above. For the purpose of this research, three positions were identified as part of the sampling unit that are; the general manager, the tourism manager or the marketing manager. 178 usable questionnaires were received out of 230 travel firms which represent a response rate of $77.39 \%$. Out of these 178 cases, there were 150 adopters and 28 non-adopters.

\section{Results, Analysis and Discussion}

The analysis tool used for the testing and interpretation of the hypotheses is regression analysis technique. Both logistic and multiple regression were used here. Logistic regression was conducted to analyse the dichotomy of adoption versus nonadoption and selling versus not selling on the web. Multiple regression was conducted to analyse simple adopters or those who use the web for communication only (zero sales via the web) with sophisticated adopters (those who use the web for communication and transactions). Thus, this research employees two dependent variables, one is a categorical variable of adopt vs. non-adopt and sell vs. not sell, and the other is a numerical variable of the percentage sales over the web.

It is important to note here that out of the 178 returned usable questionnaires, only 68 companies out of the 150 adopters answered the question about the percentage sales on the web. The rest of the adopters do not sell on the web and thus these were coded as zeros for analysis purposes. 9 companies mentioned that they sell on the web but refused to answer the question, and therefore coded as missing values. The total number of data points thus for the multiple regression model is 141 (150-9) with zeros given to all those who do not sell on the web. The regression model is based on the dimensions that were measured by the questionnaire and includes the average of the statements measuring each determinant of web adoption. Thus, imposed factors based on existing scales were used for analysis purposes. Before examining the models, an assessment of the multicollinearity in the model was conducted to prove that the variables are independent from each other or else the predictive power of any single independent variable will decrease (Hair et 
al., 1998; Diamantopoulos \& Schlegelmilch, 1997).

The test for multicollinearity was conducted by calculating the Tolerance and Variance Inflation Factor (VIF), which are reciprocals of each other, for each independent variable in order to indicate whether an independent variable can be predicted by another independent variable within the same model. If the VIF is higher than 10 , this suggests a high degree of multicollinearity (Hair et al., 1998). No high degree of multicollinearity was found within the model and thus the model is suitable for hypothesis testing. The following table (1) includes a summary of the results of the logistic regression conducted.

Table (2): Logistic Regression Model

A) Adoption Vs. Non-Adoption

\begin{tabular}{|c|c|c|c|}
\hline \multicolumn{4}{|c|}{ Model Summary } \\
\hline -2 Log Likelihood & \multicolumn{3}{|c|}{32.774} \\
\hline $\begin{array}{l}\text { Model Chi-square } \\
\text { Improvement }\end{array}$ & & $\begin{array}{ll}.840 & \mathrm{p}=0.000 \\
.840 & \mathrm{p}=0.00\end{array}$ & \\
\hline $\begin{array}{l}\text { Hosmer and Lemeshow } \\
\text { Test }\end{array}$ & \multicolumn{3}{|c|}{$1.968 \mathrm{p}=.982$} \\
\hline $\begin{array}{l}\text { Imposed Determinants of } \\
\text { Web adoption }\end{array}$ & Beta & Wald Statistic & Sig. \\
\hline \multicolumn{4}{|c|}{$\begin{array}{l}\text { Perceived Innovation Attributes } \\
\end{array}$} \\
\hline Relative advantage & 2.073 & 4.622 & .032 \\
\hline Compatibility & .228 & .156 & .693 \\
\hline Perceived risk & -.447 & .955 & .329 \\
\hline Complexity & -.805 & 4.218 & .040 \\
\hline Observability & -.663 & 1.786 & .181 \\
\hline \multicolumn{4}{|c|}{ Firm Characteristics } \\
\hline Company size & .261 & .043 & .837 \\
\hline Marketing capabilities & -.715 & 2.639 & .104 \\
\hline Organizational learning & -1.849 & 4.648 & .031 \\
\hline Employees IT knowledge & -1.247 & 4.794 & .029 \\
\hline Market orientation & .625 & .690 & .406 \\
\hline \multicolumn{4}{|c|}{ Individual Characteristics } \\
\hline Top management support & 3.773 & 11.679 & .001 \\
\hline Attitude toward change & 2.569 & 5.440 & .020 \\
\hline Response to risk & .836 & 1.634 & .201 \\
\hline
\end{tabular}

As can be seen from table 2, the chi-square test for the change in the -2 log likelihood ($2 \mathrm{LL}$ ) value from the base model is highly significant at 0.000 indicating that the model including the determinants of web adoption significantly improves our ability to predict web adoption. The small value (32.774) of the -2LL indicates a better model fit with the amount left unexplained by the model being minimal. Also, the Hosmer and Lemeshow Test of overall model fit shows that there is no statistically significant difference between the observed and predicted classifications of the dependent variable indicated by a nonsignificant chi-square value and thus a good model fit exists. 
The table shows that top management support is significant with a beta of 3.773 $(\mathrm{p}=0.001)$ and attitude toward change with a beta of $2.569(\mathrm{p}=0.020)$. Additionally, relative advantage is significant with a beta of 2.073 $(\mathrm{p}=0.032)$ and complexity is significant with a beta of $-.805 \quad(\mathrm{p}=.040)$. These results indicate that the adoption/ non-adoption decision is highly influenced by management related issues as well as the awareness of the relative advantage of the web. These are the most important factors when it comes to deciding whether to adopt or not the web. Thus, it is obvious that characteristics of management and its awareness and support to the web as well as its attitude toward the change created by the web are fundamental to the adopt/non-adopt decision. Additionally awareness of the perceived attributes of the web is important in taking the decision to adopt the web. Finally, complexity shows a significant negative effect on adoption indicating that the more complex the web is perceived, the less likely companies are to adopt it.

Contrary to previous research results, employees' IT knowledge and learning capabilities, which are part of firm resources, turn out as significant but with negative correlation on adoption. These results are not easy to explain but it may chance that these factors turn out significant in one of the models, or maybe because of the multiple models used that resulted in some ambiguity. However, these odd results occur only once across all models used. The dominant body of evidence is that organizational learning and employees' IT knowledge are not significant.

B) Sell Vs. Not Sell

\begin{tabular}{|c|c|c|c|}
\hline \multicolumn{4}{|c|}{ Model Summary } \\
\hline -2 Log Likelihood & \multicolumn{3}{|c|}{152.179} \\
\hline $\begin{array}{l}\text { Model Chi-square } \\
\text { Improvement }\end{array}$ & \multicolumn{3}{|c|}{$\begin{array}{l}55.338 \mathrm{p}=0.000 \\
55.338 \mathrm{p}=0.000\end{array}$} \\
\hline $\begin{array}{l}\text { Hosmer and Lemeshow } \\
\text { Test }\end{array}$ & \multicolumn{3}{|c|}{$5.419 \mathrm{p}=.712$} \\
\hline $\begin{array}{l}\text { Imposed Determinants of } \\
\text { Web adoption }\end{array}$ & Beta & Wald Statistic & Sig. \\
\hline \multicolumn{4}{|c|}{ Perceived Innovation Attributes } \\
\hline Relative advantage & -.395 & 1.730 & .188 \\
\hline Compatibility & -.223 & 1.335 & .248 \\
\hline Perceived risk & -.336 & 2.766 & .096 \\
\hline Complexity & -.057 & .131 & .717 \\
\hline Observability & .110 & .477 & .490 \\
\hline \multicolumn{4}{|c|}{ Firm Characteristics } \\
\hline Company size & .319 & .557 & .455 \\
\hline Marketing capabilities & 1.087 & 23.179 & .000 \\
\hline Organizational learning & -.230 & .779 & .377 \\
\hline Employees IT knowledge & -.048 & .034 & .853 \\
\hline Market orientation & -.431 & 1.262 & .261 \\
\hline \multicolumn{4}{|c|}{ Individual Characteristics } \\
\hline Top management support & -.096 & .092 & .762 \\
\hline Attitude toward change & -.240 & .772 & .395 \\
\hline Response to risk & .526 & 3.151 & .076 \\
\hline \multicolumn{4}{|l|}{ Percentage correctly classifi } \\
\hline
\end{tabular}


As can be seen from the above table, the chisquare test for the change in the -2 log likelihood (-2LL) value from the base model is highly significant at 0.000 , indicating that the model involving the determinants of web adoption significantly improves our ability to predict web adoption. The value of the -2LL indicates a better model fit. Also, the Hosmer and Lemeshow Test of overall model fit shows that there is no statistically significant difference between the observed and predicted classifications of the dependent variable indicated by a non-significant chisquare value and thus a good model fit exists.

The table shows that two factors (marketing capabilities and response to risk) are positively correlated and significant in relation to selling on the web. Additionally, one factor (perceived risk) is significant but negatively correlated. The magnitude of the relations is presented by the beta coefficients. Marketing capabilities is significant with a beta value of 1.087 $(\mathrm{p}=.000)$ and response to risk with a beta value of $.526(p=.076)$. These results suggest that the simple versus sophisticated adoption decision is highly influenced by the marketing capabilities existing within the firm and that these capabilities are fundamental for a travel firm to be able to sell on the web. Additionally, response to risk comes directly after marketing capabilities in terms of influence and significance and this indicates that selling on the web requires management to be able to take risks and be less conservative in terms of the decisions they make regarding the web. Additionally, perceived risk has a significant negative influence on selling on the web with a beta of -.336 ( $\mathrm{p}=.096)$, suggesting that travel companies are concerned about the risks associated with online payment and the risks of losing travel business with their tour operators as a result of selling directly on the web. This implies knowledge of these risks does have a negative impact on deciding to sell or not to sell on the web.

It is worth mentioning that none of the firm resources other than marketing capabilities turned out significant here, suggesting that Knowledge of IT, being market-oriented or having a certain level of learning within the organization are not important factors influencing selling over the web, the ability to sell is determined by possessing the marketing capability for doing that. Moreover, management does not turn out as a significant factor affecting selling or not selling on the web. Finally, the bottom row of the table shows a high hit ratio (76\%) for correctly classified cases for the model. This ratio indicates that the model performs well in terms of predicting the number of observed simple and sophisticated adopters.

Having discussed the results of the logistic regression model, table (3) below discusses the results of the multiple regression model that deals with the percentage of sales conducted over the web. 
Table (3): Multiple Regression Model

\begin{tabular}{|c|c|c|c|}
\hline \multicolumn{4}{|l|}{ Model Summary } \\
\hline $\mathbf{R}$ & \multicolumn{3}{|l|}{0.646} \\
\hline R square & \multicolumn{3}{|l|}{0.418} \\
\hline Adjusted R square & \multicolumn{3}{|l|}{0.358} \\
\hline $\mathbf{F}$ & \multicolumn{3}{|l|}{7.014} \\
\hline Sig. & \multicolumn{3}{|l|}{0.000} \\
\hline df1 & \multicolumn{3}{|l|}{13} \\
\hline df2 & \multicolumn{3}{|l|}{127} \\
\hline $\begin{array}{l}\text { Imposed Determinants of } \\
\text { Web adoption }\end{array}$ & \multicolumn{2}{|c|}{$\begin{array}{l}\text { Standardized } \\
\text { Coefficients }\end{array}$} & $\begin{array}{l}\text { Collinearity } \\
\text { Diagnostics }\end{array}$ \\
\hline & Beta & Sig. & Variable inflation factor (VIF) \\
\hline \multicolumn{4}{|c|}{ Perceived Innovation Attributes } \\
\hline Relative advantage & -.049 & .542 & 1.432 \\
\hline Compatibility & -.047 & .604 & 1.808 \\
\hline Perceived risk & -.182 & .023 & 1.363 \\
\hline Complexity & .002 & .981 & 1.316 \\
\hline Observability & .088 & .253 & 1.276 \\
\hline \multicolumn{4}{|l|}{ Firm Resources } \\
\hline Company size & -.008 & .915 & 1.100 \\
\hline Marketing capabilities & .577 & .000 & 1.805 \\
\hline Organizational learning & .041 & .612 & 1.403 \\
\hline Employees IT knowledge & -.017 & .837 & 1.576 \\
\hline Market orientation & -.077 & .344 & 1.438 \\
\hline \multicolumn{4}{|c|}{ Individual Characteristics } \\
\hline Top management support & -.076 & .447 & 2.194 \\
\hline Attitude toward change & -.142 & .110 & 1.201 \\
\hline Response to risk & .160 & .062 & 1.582 \\
\hline
\end{tabular}

The above table shows that the independent factors account for $35.8 \%$ of the variance in web adoption represented by the adjusted $\mathrm{R}^{2}$ (Hair et al., 1998). This is again a relatively adequate level of explanatory power given the sample size and the number of independent variables considered. Additionally, the significant $\mathrm{F}$, as presented in the table, reflects a significant value of .000 . These results support the suggested conceptual framework. The table shows that from the thirteen determinants of web adoption, two are positively correlated and significant in relation to web adoption. One factor is negatively correlated and significant in relation to web adoption. The magnitude of the relationships is presented by the beta coefficients. Beta values show that marketing capabilities is the variable that has the largest influence on web adoption with a beta value of .586 $(\mathrm{p}=.000)$. Following is the perceived risk with a beta of $-.182(\mathrm{p}=.023)$. And finally, response to risk with a beta of $.160(\mathrm{p}=.062)$.

These results show that perceived risk is a significant factor with regard to more sophisticated levels of web adoption, indicating that travel companies are concerned about the risks associated with online payment and the risks of losing travel business with their tour operators as a result of selling directly on the web. This implies that knowledge of these risks does have a negative impact on deciding to sell or not to sell on the web; and hence the degree of web adoption.

Thus, the hypotheses that will be accepted under perceived innovation attributes are 
relative advantage and complexity for likelihood of adoption and perceived risk for levels of adoption.

As for firm characteristics, organizational learning and employees' IT knowledge not turning out as significant factors in simple versus sophisticated adoption further support the same argument that the willingness to sell on the web is not affected by the internal IT knowledge or learning within the organization, since the organization can rely on an external consultant to do the technical part related to developing a web site. Selling on the web requires marketing ability to do that rather than technical IT knowledge.

Thus, the hypothesis that will be accepted under firm resources is the one related to marketing capabilities.

In individual characteristics, management support and attitude toward change turned out as significant factors on the likelihood of adoption, and response to risk turned out as an influential and significant factor on simple versus sophisticated adoption. This indicates that in order to adopt the web, management has to first have an awareness of the benefits and a desire to go through the changes required. On the other hand, in order to be willing to sell on the web, management must be risk takers rather than conservative in terms of the decisions they make regarding their business on the web.

Thus the hypotheses that will be accepted under individual factors are management support and attitude toward change for likelihood of adoption as well as response to risk for levels of adoption.

\section{Conclusion}

This paper has attempted to enhance current understanding of the adoption of innovations with a particular focus on the factors that might influence businesses to adopt the web for marketing purposes. This research represents an extension to the rather limited literature on organizations' adoption of innovations and focuses in particular on SMEs. The research context, Egypt, is of particular interest given that the innovation web- is still at a relatively early stage of development. The model was tested using logistic and multiple regression and results indicate support of the model.

This research found that four factors affect the likelihood of adoption namely; relative advantage, complexity, top management support and attitude toward change. This indicates that when it comes to make a decision of whether to adopt the internet or not, perceived innovation attributes come into play and exert an influence. Additionally, whether management supports the idea or not has an important influence on the likelihood of adoption.

It also found that three factors affect the level of web adoption among travel SMEs that are perceived risk, marketing capability and response to risk. As for perceived risk, this research found that for more advanced levels of adoption which include selling on the web, more risks are associated with making online payment and securing the full transaction online. Thus, those considering more advanced levels of adoption are aware of these risks and it has a negative impact on them. This might indicate that the web is being used much more for promotion rather than for distribution out of security concerns related to conducting a complete online transaction.

As for firm resources, marketing capability was found to be a highly significant factor with a positive relationship with simple versus sophisticated adoption of the web. Marketing capability deals with the ability of travel agents to develop, promote and distribute travel services over the web. The research results show that this factor is relevant to sophisticated levels of adoption since a significant positive relation between marketing capabilities and the level of web adoption was found. Thus, when it comes to more sophisticated levels of adoption of the 
web, having the ability to market a travel product on the web becomes fundamental.

Finally, management's response to risk has a significant positive relation with simple versus sophisticated adoption, indicating that companies willing to make more advanced levels of adoption of the web are more likely to take the risks associated with the web, such as security risks related to online payment.

\section{Limitations and Future Research}

Like any social science research, this research has a number of limitations. First, the small sample size for the multiple regression model presents a limitation. For the more sophisticated measure of how much do you sell on the web, only 79 companies out of the 150 adopters do sell on the web of which 11 refused to answer the question. The rest of the companies do not sell on the web and thus these were coded as zeros resulting in a large number of zeros for this analysis.

Second, the selected sample is a convenience sample and in spite of the advantages of selecting such a sample, it places some limitations in terms of generalizability of the results. Third, the data and findings in the analysis chapters were derived from research in a single country and a single sector which is the tourism sector. This raises questions as to the generalizability of the results of this research to different cultures. As such, the results and discussions are applicable particularly to the Egyptian context, but may also provide insights to the travel industry in other countries.

The area of web marketing and in particular the adoption of the web by organizations is considered important and still needs more conceptual and empirical contributions. Hence, a number of directions for future research exist as follows:

Researchers can apply the framework of the determinants of web adoption used here including Roger's theory of innovation adoption and the Resource-based View of the firm to another service other than the tourism service to be able to generalize it. Also researchers can do a cross cultural analysis by applying this framework to the tourism industry in another country to compare the results of this research in terms of whether the same factors turn out as significant and to be able to generalize the framework in different cultures. Another direction for research would be to make a modification to the research model studied here by including both firm and consumer sides in the same model. Finally, future studies on organizational adoption of the web could incorporate both adopter-side variables and supply-side variables when considering the adoption of innovations

\section{References}

Aguila-Obra, A. \& Padilla-Melendez, A. (2006). "Organizational Factors Affecting Internet Technology Adoption," Internet Research 16 (1), Pp.94-110.

Akgun, A. E., Keskin, H., Byrne, J. C. \& Aren, S. (2007). "Emotional and Learning Capability and Their Impact on Product Innovativeness and Firm Performance," Technovation 27, Pp.501-513.

Barney, J. (1991). "Firm Resources and Sustained Competitive Advantage," Journal of Management 17(1), Pp.99-120.

Bauer, R. A. (1960). 'Consumer Behaviour as Risk Taking,' Proceedings of the Educators Conference, American Marketing Association, Pp.389-398.

Bayo-Moriones, A. \& Lera-Lopez, F. (2007). "A Firm-Level Analysis of Determinants of ICT Adoption in Spain," Technovation 27, Pp. 352-366.

Beatty, R. C., Shim, J. P. \& Jones, M. C. (2001). "Factors Influencing Corporate Web Site Adoption: A Time-Based Assessment," Information and Management 38, Pp.337354. 
19 Journal of Innovation Management in Small \& Medium Enterprises

Benedetto, C. A., Desarbo, W. S. \& Song, M. (2008). "Strategic Capabilities and Radical Innovation: And Empirical Study in Three Countries," IEEE Transactions on Engineering Management 55 (3), Pp.420-433.

Bengtsson, M., Boter, H. \& Vanyushyn, V. (2007). "Integrating the Internet and Marketing Operations: A Study of Antecedents in Firms of Different Size," International Small Business Journal 25 (1), Pp.27-48.

Bharati, P. \& Chaudhury, A. (2006). "Studying the Current Status of Technology Adoption," Communications of the ACM 49 (10), Pp.8893.

Black, N. J., Lockett, A., Winklhofer, H. \& Ennew, C. (2001). "The Adoption of Internet Financial Services: A Qualitative Study," International Journal of Retail and Distribution Management 29 (8), Pp.390-398.

Brancheau, J. C. \& Wetherbe, J. C. (1990). "The Adoption of Spreadsheet Software: Testing Innovation Diffusion Theory in the Context of End-User Computing," Information Systems Research 1 (2), Pp.115-143.

Brand, M. J. \& Huizingh, E. K. R. A. (2008). "Into the Drivers of Innovation Adoption What Is the Impact of the Current Level of Adoption?," European Journal of Innovation Management 11 (1), Pp.5-24.

Bruque, S. \& Moyano, J. (2007). "Organizational Determinants of Information Technology Adoption and Implementation in Smes: The Case of Family and Cooperative Firms," Technovation 27, Pp.241-253.

Calantone, R. J., Cavusgil, S. T. \& Zhao, Y. (2002). "Learning Orientation, Firm Innovation Capability, and Firm Performance," Industrial Marketing Management 31, Pp.515-524.
Chipika, S. \& Wilson, G. (2006). "Enabling Technological Learning among Light Engineering Smes in Zimbabwe through Networking," Technovation 26, Pp.969-979.

Chong, S. \& Pervan, G (2007). "Factors Influencing the Extent of Deployment of Electronic Commerce for Small-and MediumSized Enterprises," Journal of Electronic Commerce in Organizations 5 (1), Pp.1-29.

Chong, S. C. \& Lin, B. (2008). "Exploring Knowledge Management KM Issues and KM Performance Outcomes: Empirical Evidence from Malaysian Multimedia Super Corridor Companies," Sssssss 43 (4), Pp.285-303.

Colombo, M. G. \& Delmastro, M. (2001). "Technology-Based Entrepreneurs: Does Internet Make a Difference?," Small Business Economics 16 (3), Pp.177-190.

Corbitt, B. J. (2000). "Developing Intraorganizational Electronic Commerce Strategy: An Ethnographic Study," Journal of Information Technology 15, (2), Pp.119-130.

Cragg, P. J. \& King, M. (1993). "Small Firm Computing: Motivators and Inhibitors," MIS Quarterly 17 (1), Pp.47-60.

Damanpour, F. (1992). "Organization Size and Innovation," Organization Studies 13, Pp.375-402.

Dandridge, T. \& Levenburg, N. M. (2000). "High-Tech Potential? An Exploratory Study of Very Small Firms' Usage of The Internet," International Small Business Journal 18 (2), Pp.81-91.

Daniel, E., Wilson, H. \& Myers, A. (2002). "Adoption of E-Commerce by Smes in the UK: Towards a Stage Model," International Small Business Journal 20 (3), Pp.253-270. 
Day, G. S. (1994). "The Capabilities of MarketDriven Organizations," Journal of Marketing 58, Pp.37-51.

Dholakia, R. R. \& Kshetri, N. (2004). "Factors Impacting the Adoption of the Internet among SMEs," Small Business Economics 23, Pp.311-322.

Diamantopoulos, A. \& Schlegelmilch, B. (1997). Taking the Fear Out of Data Analysis: A Step by Step Approach, The Dryden Press.

Dicksen, P. R. (1996). "The Static and Dynamic Mechanics of Competition: A Comment on Hunt and Morgan's Comparative Advantage Theory," Journal of Marketing 60, (October), Pp.102-106.

Doherty, N., Ellis-Chadwick, F. \& Hart, C. (2003). "An Analysis of the Factors Affecting the Adoption of the Internet in the UK Retail Sector," Journal of Business Research 56, Pp.888-897.

Dubelaar, C., Sohal, A. \& Savic, V. (2005). "Benefits, Impediments and Critical Success Factors in B2C E-Business Adoption," Technovation 25 (11), Pp.1251-1262.

Fabiani, S., Schivardi, F. \& Trento, S. (2005). "ICT Adoption in Italian Manufacturing: Firm-Level Evidence," Industrial and Corporate Change 14 (2), Pp.225-249.

Ferneley, A. \& Bell, F. (2006). "Using Bricolage to Integrate Business and Information Technology Innovation in SMEs," Technovation 26 (2), Pp. 232-241.

Fillis, I. \& Wagner, B. (2007). "E-Business Development: An Exploratory Investigation of the Small Firm," International Small Business Journal 23 (6), Pp.604-634.

Frambach, R. T., Barkema, H. G., Nooteboom, B. \& Wedel, M. (1998). "Adoption of a Service Innovation in the Business Market: An Empirical Test of Supply-Side Variables," Journal of Business Research 41, Pp.161-174.
Frambach, R. T. \& Schillewaert, N. (2002). "Organizational Innovation Adoption: A Multi-Level Framework of Determinants and Opportunities for Future Research," Journal of Business Research, 55, (2) Pp 163-176.

Goode, S. \& Stevens, K. (2000). "An Analysis of the Business Characteristics of Adopters and Non-Adopters of World Wide Web Technology," Information Technology and Management 1, Pp.129-154.

Grandson, E. E. \& Pearson, J. M. (2004). "Electronic Commerce Adoption: An Empirical Study of Small and Medium US Businesses," Information and Management 42, Pp.197-216.

Guenzi, P. \& Troilo, G. (2007). "The Joint Contribution of Marketing and Sales to the Creation of Superior Customer Value," Journal of Business Research 60 (2), Pp.98107.

Hair, J. F., Anderson, R. E., Tatham, R. L. \& Black, W. (1998). 'Multivariate Data Analysis,' Prentice Hall, Inc., Upper Saddle River, New Jersey.

Hamill, J. \& Gregory, K. (1997). "Internet Marketing in the Internationalization of UK SMEs," Journal of Marketing Management 13, Pp.9-28.

Hoffman, D. L. \& Novak, T. P. (1997). "A New Marketing Paradigm for Electronic Commerce," The Information Society, 13 (1), Pp.43-54.

Hooley, G., Broderick, A. \& Moller, K. (1998). "Competitive Positioning and the ResourceBased View of the Firm," Journal of Strategic Marketing 6, Pp.97-115.

Houghton, K. A. \& Winklhofer, H. (2002). 'Internet Adoption in Exporting Smes: Development of a Conceptual Model,' American Marketing Association, Conference Proceedings, Chicago 13, P.504. 
Huizingh, E. K. R. E. \& Brand, M. J. (2009). "Stepwise Innovation Adoption: A Neglected Concept in Innovation Research," International Journal of Technology Management 45, (3/4), Pp.267-281.

Hurley, R. F. \& Hult, G. T. M. (1998). "Innovation, Market Orientation, and Organizational Learning: An Integration and Empirical Examination," Journal of Marketing 62, Pp.42-54.

Jimenez-Jimenez, D., Valle, R. S. \& HernandezEspallardo, M. (2008). "Fostering Innovation: The Role of Market Orientation and Organizational Learning," European Journal of Innovation Management 11 (3), Pp.389412.

Kartiwi, M. \& Macgregor, R. C. (2007). "Electronic Commerce Adoption Barriers in Small to Medium-Sized Enterprises (Smes) in Developed and Developing Countries: A Cross-Country Comparison," Journal of Electronic Commerce in Organizations 5 (3), Pp.35-51.

Keeny, D. \& Marshall, J. F. (2000). "Contextual Marketing: The Real Business on the Internet," Harvard Business Review, Nov-Dec, Pp.119-125.

Kimberly, J. R. \& Evanisko, M. J. (1981). "Organizational Innovations: The Influence of Individual, Organizational, and Contextual Factors on Hospital Adoption of Technological and Administrative Innovations," Academy of Management Journal 24, Pp.689-713.

Krasnikov, A. \& Jayachandran, S. (2008). 'The Relative Impact of Marketing, Research-andDevelopment, and Operations Capabilities of Firm Performance,' Journal of Marketing 72 (4), Pp.1-11.

Lefebvre, L. A., Lefebvre, E., Elia, E. \& Boeck, H. (2005). "Exploring B-To-B E-Commerce Adoption Trajectories in Manufacturing SMEs," Technovation 25, Pp. 1443-1456.
Leskovar-Spacapan, G. \& Bastic, M. (2007). "Differences in Organizations' Innovation Capability in Transition Economy: Internal Aspect of the Organizations' Strategic Orientation," Technovation 27, Pp.533-546.

Lockett, A. \& Littler, D. (1997). "The Adoption of Direct Banking Services," Journal of Marketing Management 13, Pp.791-811.

Lockett, A. \& Thompson, S. (2001). "The Resource-Based View and Economics," Journal of Management 27, Pp.723-754.

Maguire, S., Koh, S. C. L. \& Magrys, A. (2007). "The Adoption of E-Business and Knowledge Management in SMEs", Benchmarking: An International Journal 14 (1), Pp.37-58.

Malhotra, P. \& Singh, B. (2007). "Determinants of Internet Banking Adoption by Banks in Spain," Internet Research 17 (3), Pp.323-339.

Molla, A. \& Licker, P. S. (2005). "eCommerce Adoption in Developing Countries: A Model and Instrument," Information and Management 42, Pp.877-899.

Narver, J. C. \& Slater, S. F. (1990). "The Effect of a Market Orientation on Business Profitability," Journal of Marketing 54, Pp.2035.

Poon, J. P. H. \& MacPherson, A. (2005). "Innovation Strategies of Asian Forms in the United States," Journal of Engineering Technology Management 22, Pp.255-273.

Premkumar, G. \& Roberts, M. (1999). "Adoption of New Information Technologies in Rural Small Businesses," Omega International Journal of Management Science 27, Pp.467-484.

Real, J. C., Leal, A. \& Roldan, J. L. (2006). "Information Technology as a Determinant of Organizational Learning and Technological Distinctive Competencies," Industrial Marketing Management 35 (4), Pp.505-521. 
Rogers, E. M. (1962). Diffusion of Innovations, 1st Ed. New York: The Free Press.

Rogers, E. M. (2003). Diffusion of Innovations, 5th Ed. New York: The Free Press.

Ruiz-Ortega, M. J. \& Garcia-Villaverde, P. M. (2008). "Capabilities and Competitive Tactics Influences on Performance: Implications of the Moment of Entry," Journal of Business Research 61 (4), Pp.332-345.

Saffu, K., Walker, J. H. \& Hinson, R. (2008). "Strategic Value and Electronic Commerce Adoption among Small and Medium Sized Enterprises in a Transitional Economy," Journal of Business and Industrial Marketing 23 (6), Pp.395-404.

Salavou, H., Baltas, G. \& Lioukas, S. (2004). "Organizational Innovation in SMEs: The Importance of Strategic Orientation and Competitive Structure," European Journal of Marketing 38 (9/10), Pp.1091-1112.

Schillewaert, N., Ahearne, M. J., Frambach, R. T. \& Moenaert, R. K. (2005). "The Adoption of Information Technology in the Sales Force," Industrial Marketing Management 34 (4), 323-336.

Scupola, A. (2003). "The Adoption of Internet Commerce by SMEs in the South of Italy: An Environmental, Technological and Organizational Perspective," Journal of Global Information Technology Management 6 (1), Pp.52-71.

Shim, S., Eastlick, M. A., Lotz, S. L. \& Warrington, P. (2001). "An Online Prepurchase Intentions Model: The Role of Intention to Search," Journal of Retailing (77), Pp. 397-416.

Sinkula, J. M., Baker, W. E. \& Noordewier T. (1997). "A Framework for Market-Based Organizational Learning: Linking Values, Knowledge, and Behavior," Journal of the Academy of Marketing Science 25 (4), Pp.305318.
Song, J. H. \& Zinkhan, G. M. (2008). "Determinants of Perceived Website Interactivity," Journal of Marketing 72, Pp.99113.

Sultan, F. \& Chan, L. (2000). "The Adoption of New Technology: The Case of ObjectOriented Computing in Software Companies," IEEE Transactions on Engineering Management 47 (1), Pp.106-126.

Tabak, F. \& Barr, S. H. (1996). "Adoption of Organizational Innovations: Individual and Organizational Determinants," Academy of Management Proceedings Pp.388-392.

Tan, J., Tyler, K. \& Manica, A. (2007). "Business-to-Business Adoption of Ecommerce in China," Information and Management 44, Pp.332-351.

Tan, K., Chong, S. \& Uchenna, C. (2009). "Factors Influencing the Adoption of Internet-Based Icts: Evidence from Malaysian Smes," International Journal of Management and Enterprise Development (In Press). In Tan, K. S., Chong, S. C., Lin, B. \& Eze, U. C. (2008). "Internet-Based ICT Adoption: Evidence from Malaysian Smes," Industrial Management and Data Systems 109 (2), Pp.224-244.

Teo, T. S. H. \& Pian, Y. (2003). "A Contingency Perspective on Internet Adoption and Competitive Advantage," European Journal of Information Systems 12, Pp.78-92.

Teo, T. S. H. \& Ranganathan, C. (2004). "Adopters and Non-Adopters of Business-toBusiness Electronic Commerce in Singapore," Information and Management 42, Pp.89-102.

Thong, J. (1999). "An Integrated Model of Information Systems Adoption in Small Businesses," Journal of Management Information Systems 15 (4), Pp.187-214.

To, M. L. \& Ngai, E. W. T. (2006). "Predicting Organizational Adoption of B2C ECommerce: An Empirical Study," Industrial 
Management and Data Systems 106, No.8, Pp.1133-1147.

Walczuch, R., Van Braven, G. \& Lundgren, H. (2000). "Internet Adoption Barriers for Small Firms in the Netherlands," European Management Journal 18 (5), Pp.561-572.

Wan, D., Ong, C. H. \& Lee, F. (2005). "Determinants of Firm Innovation in Singapore," Technovation 25, Pp.261-268.

Webb, B. \& Sayer, R. (1998). "Benchmarking Small Companies in the Internet," Long Range Planning 31 (6), Pp.815-827.

Weerawardena, J. (2003). "The Role of Marketing Capability in Innovation-Based Competitive Strategy," Journal of Strategic Marketing 11, Pp.15-35.

Weerawardena, J. \& O'Cass, A. (2004). "Exploring the Characteristics of the MarketDriven Firms and Antecedents to Sustained Competitive Advantage," Industrial Marketing Management 33, Pp.419-428.

Wright, P. M., Mcmahan, G. C. \& Mcwilliams, A. (1994). "Human Resources and Sustained Competitive Advantage: A Resource-Based Perspective," International Journal of Human Resource Management 5 (2), Pp.301-326.

Yoh, E., Damhors, M. L., Sapp, S. \& Laczniak, R. (2003). "Consumer Adoption of the Internet: The Case of Apparel Shopping," Psychology \& Marketing 20 (12) (December), Pp. 10951118. 